\title{
ORQUÍDEAS DE BOLIVIA Y PERÚ, NOVEDADES TAXONÓMICAS I (PLEUROTHALLIDINAE)
}

\author{
IVÁN JiMÉNEZ PÉREZ \\ Herbario Nacional de Bolivia, Correo Central 10077, La Paz, Bolivia \\ suniruna@gmail.com
}

\begin{abstract}
RESUMEN. Se describen e ilustran siete especies nuevas de orquídeas pertenecientes a la subtribu Pleurothallidinae de los bosques montanos de la Cordillera Oriental de los Andes, seis de ellas Bolivia y una de Bolivia y Perú,: Brachionidium lopez-robertsiae, Brachionidium sulcatum, Lepanthopsis trulliformis, Stelis pertusa, Trichosalpinx adnata, Trichosalpinx gabi-villegasiae y Trichosalpinx giovi-mendietae. De cada especie se proporcionan datos de hábitat, distribución y fenología. Además se comentan rasgos sobresalientes y afinidades con especies similares.
\end{abstract}

AbSTRAct. Seven new orchids species belonging to the subtribe Pleurothallidinae from the montane forest of the eastern Andean slopes, six of them from Bolivia and one from Bolivia and Peru, are described and illustrated: Brachionidium lopez-robertsiae, Brachionidium sulcatum, Lepanthopsis trulliformis, Stelis pertusa, Trichosalpinx adnata, Trichosalpinx gabi-villegasiae and Trichosalpinx giovi-mendietae. Information on habitat, distribution and phenology is provided for each species. Also critical characters and affinities with similar species are commented.

Palabras clave: bosque montano, orquídeas, Cotapata, Madidi, Tayacaja, Pleurothallidinae

Introducción. Orchidaceae es una de las dos familias más diversas de las plantas superiores junto a Asteraceae y en ambas alrededor de 500 especies nuevas son descritas cada año (Chase et al. 2015). En Bolivia este panorama es similar ya que las dos familias son los taxa más grandes de la flora boliviana (Jørgensen et al. 2014). Desde inicios de la década de 1980 hasta mediados del 2000 la publicación de nuevos taxa fue constante, especialmente en los trabajos de R. Vásquez con C. Luer y C.H. Dodson (ver Luer 1981, 1983a, 1983b, 1995, 1997, 1999, 2001, Dodson \& Vásquez 1989a, 1989b, Vásquez \& Dodson 1982, 1998, 1999, 2001), lo cual condujo a que la subtribu Pleurothallidinae sean las orquídeas mejor conocidas del país (Vásquez \& Ibisch, 2000). Aunque la descripción de nuevas especies o registros no ha cesado, la intensidad ha disminuido en los últimos años. Actualmente se conocen en Bolivia 1264 especies de orquídeas (Vásquez et al. 2014), pero si se toman en cuenta las especies no identificadas esta cifra asciende a alrededor de 1500, estimando que existan entre 2000 a 3000 en el país (Vásquez et al.2003). Desde hace 10 años se han encontrado muchas novedades taxonómicas en los viajes realizados a varias zonas de los bosques montanos del departamento de La Paz, ya sea como parte de proyectos ligados al estudio de otras plantas o emprendimientos personales. Algunos resultados fueron publicados por Jiménez-Pérez (2011a, 2011b, 2012).

Este artículo está orientado por un lado a la descripción e ilustración de novedades taxonómicas procedentes de los viajes realizados y revisión de muestras depositadas en herbarios nacionales y por otro lado a generar material para futuros tratamientos taxonómicos. En este primer aporte se describen 7 nuevos taxa de Pleurothallidinae, pertenecientes a los géneros: Brachionidium Lindl., Lepanthopsis (Cogn.) Ames, Stelis Sw. sensu lato y Trichosalpinx Luer.

\section{Nuevos TAXA}

\section{Brachionidium lopez-robertsiae I.Jiménez, sp. nov.}

TIPO: Bolivia. La Paz: Provincia Nor Yungas, Parque Nacional Cotapata, $67^{\circ} 52^{\prime} \mathrm{O}, 16^{\circ} 15^{\prime} \mathrm{S}, 3200 \mathrm{~m}, 17$ 


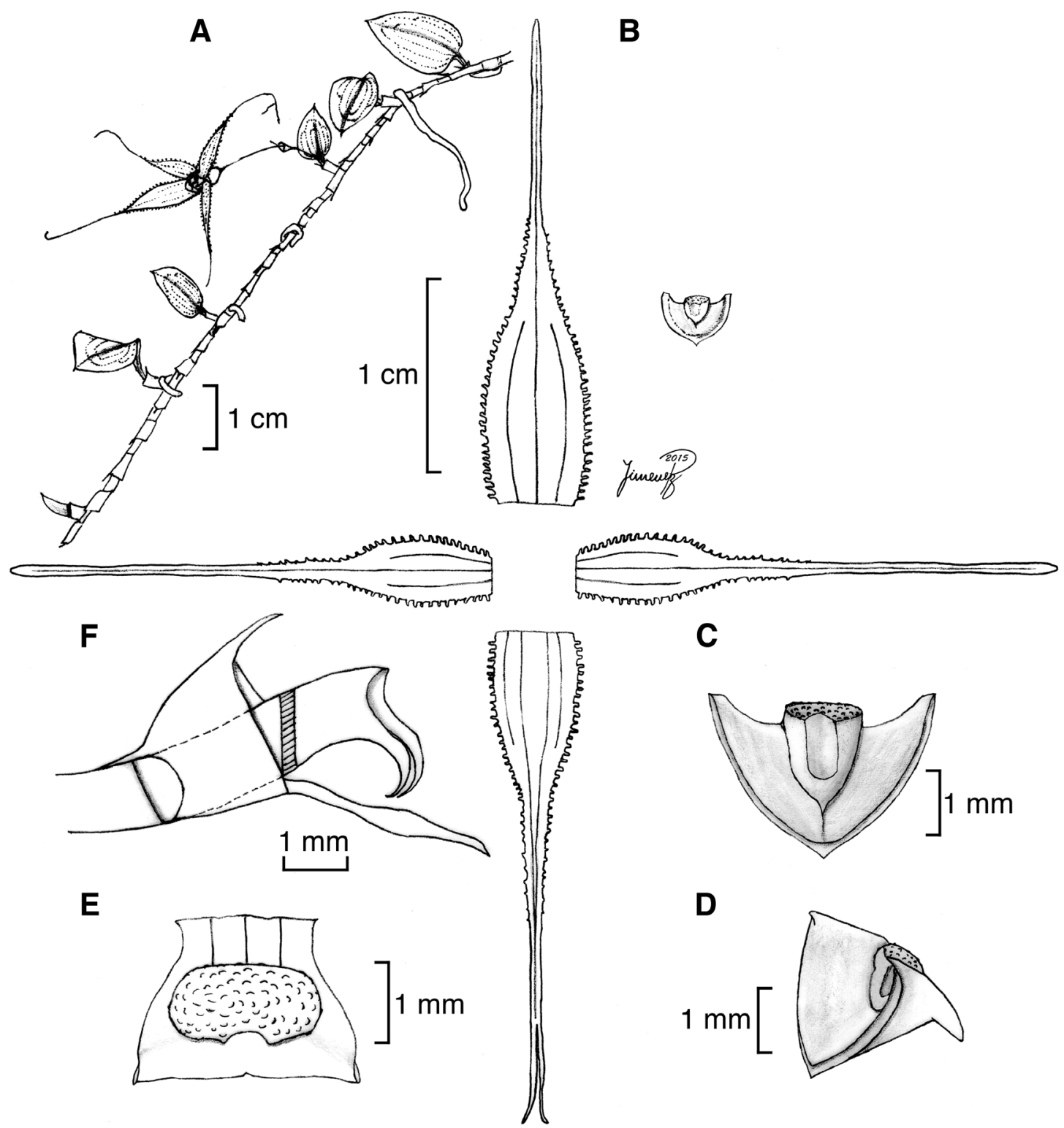

Figura 1. Brachionidium lopez-robertsiae. A. Hábito. B. Flor diseccionada. C. Labelo vista frontal. D. Labelo vista lateral. E. Labelo vista dorsal. F. Columna vista lateral. Dibujo a partir del holotipo de I. Jiménez Pérez

diciembre 2010, I. Jiménez et al. 5620 (holotipo: LPB). Figs. 1, 3A, 3B.

This species is similar to B. capillare Luer \& Hirtz and B. muscosum Luer \& Vásquez, but differs from both by the ovate-elliptic to suborbiculate leaves, the large flowers with ciliates sepals and petals, the bimarginate labellum with a suborbiculate verrucose callus and the bidentate column with retrorse apices.
Hierba terrestre o epífita, largamente rastrera, hasta $3.6 \mathrm{~cm}$ de alto. Rizoma ramificado, una raíz por nudo, entre tallos adyacentes cubierto por 3 vainas tubulares, oblicuas y mucronadas. Tallo suberecto a erecto, 10 24(-39) mm de separación entre tallos adyacentes, 2-5 $\mathrm{mm}$ de largo, cubierto por (1)2 vainas, ligeramente oblicuas, mucronadas. Hoja patente, coriácea, ovadoelíptica a suborbicular, apiculada, 8-17 × 5.0-11.5 
$\mathrm{mm}$, de 7 venas, base redondeada, peciolo sulcado, 2-3 mm de largo. Inflorescencia erecta, uniflora, pedúnculo delgado, con una bráctea al medio y otra en la base, 14-22 mm de largo; bráctea floral en forma de embudo, mucronata, que envuelve el pedicelo y casi totalmente el ovario, $2 \mathrm{~mm}$ de largo; pedicelo $1 \mathrm{~mm}$ de largo; filamento $3 \mathrm{~mm}$ de largo; ovario 2 $\mathrm{mm}$ de largo. Flor no resupinada, perianto amarillo claro verdoso, ciliado, sépalos laterales y pétalos con rayas longitudinales tenuemente moradas, carinados sobre la vena central, caudas moradas, retrorsas, disco morado al igual que la base de la columna; sépalo dorsal elíptico, agudo, $25 \times 5 \mathrm{~mm}$ incluyendo la cauda, de 3 venas, largamente caudado, cauda 10 $\mathrm{mm}$ de largo; sépalos laterales unidos en un sinsépalo lanceolado, agudo, $5 \mathrm{~mm}$ bífido en el ápice, $25 \times 5 \mathrm{~mm}$ incluyendo la cauda, de 4 venas, largamente caudado, cauda $10 \mathrm{~mm}$ de largo; pétalo elíptico, ligeramente oblicuo, agudo, $25 \times 3 \mathrm{~mm}$ incluyendo la cauda, de 3 venas, largamente caudado, cauda $13 \mathrm{~mm}$ de largo; labelo subcordato de frente, cortamente apiculado, bimarginado, $2.5 \times 3.5 \mathrm{~mm}$ no expandida, de 3 venas, apéndices laterales erguidos, subagudos y levemente antrorsos, disco con un callo subgloboso, verrucoso, glenion notorio; columna recta, bidentada, de ápices retrorsos, 1.5-2.0 mm de largo; polinario no visto.

Paratipo: BOliVia. La Paz: Nor Yungas, Hornuni

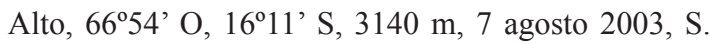
Beck et al. 28783 (LPB).

DisTRIBUCIÓN Y ECOLOGÍA: Especie registrada hasta ahora exclusivamente en el norte y sur del Parque Nacional y Área Natural de Manejo Integrado (PNANMI) Cotapata, departamento de La Paz. Habita el bosque nublado de ceja de montaña, poco perturbado, dominado por árboles de Clusia spp. Forma matas densas en el suelo del sotobosque donde hay formación de humus. Posee una estrecha distribución altitudinal, 3100-3200 m. Florece en diciembre y enero.

Etimología: Esta especie se dedica a María Cristina López Roberts, amiga y colega con buen ojo para descubrir nuevas e interesantes orquídeas, quien alentó y acompaño entusiastamente muchos viajes a la zona de estudio, además de ser una de las promotoras del proyecto que inició el estudio de orquídeas y otras plantas epífitas en el PN-ANMI Cotapata.
Brachionidium lopez-robertsiae se distingue por su rizoma largamente rastrero, hojas ovadas a casi orbiculares, perianto ciliado, largamente caudado, labelo bimarginado con callo verrucoso y columna bidentada con ápices notoriamente retrorsos. Vegetativamente se asemeja a $B$. capillare por tener habito rastrero, hojas orbiculares y flores caudadas; $\sin$ embargo, este último posee sépalos y pétalos eciliados, más cortos, de 13 y $10 \mathrm{~mm}$ respectivamente y ápice del labelo largamente apiculado (Luer 1995). Localmente solo B. muscosum comparte un rizoma largamente rastrero y perianto fimbriado pero los sépalos y pétalos son cortos, de 10.0-10.5 y $7 \mathrm{~mm}$ respectivamente y las hojas son elípticas (Luer, 1995). Esta orquídea corresponde a una de las dos especies nuevas citadas en Vásquez et al. (2014).

\section{Brachionidium sulcatum I.Jiménez, sp. nov.}

TIPO: Bolivia La Paz: Provincia Nor Yungas, Parque Nacional Cotapata, $67^{\circ} 53^{\prime} \mathrm{O}, 16^{\circ} 16^{\prime} \mathrm{S}, 3387 \mathrm{~m}, 17$ diciembre 2010, I. Jiménez 5619 (holotipo: LPB; isotipo: BOLV). Figs. 2, 3C, 3D.

This species is related to B. galeatum Luer \& Hirtz, but differs in the creeping rhizome, the subcoriaceous narrowly oblong leaves, with a pair of grooves, and the flowers with a slightly bifurcate synsepal and a partially bimarginate labellum with a subglobose callus.

Hierba pequeña, epigea sobre colchón de musgo, largamente rastrera, hasta $6.5 \mathrm{~cm}$ de alto. Rizoma decumbente, poco ramificado, una raíz por nudo, entre tallos adyacentes cubierto por vainas tubulares, mucronatas, escabriúsculas. Tallo suberecto, 13-25 $\mathrm{mm}$ de separación entre tallos adyacentes, cubierto por 2 vainas, mucronatas, 3-5 $\mathrm{mm}$ de largo. Hoja patente, subcoriácea, oblonga, apiculada, 2-sulcado, $11-20 \times 1.0-2.5 \mathrm{~mm}$, de 3 venas, base cortamente atenuado, peciolo sulcado, $0.5-1.0 \mathrm{~mm}$ de largo. Inflorescencia erecta, uniflora, pedúnculo con una bráctea al medio y otra en la base, 7-16 mm de largo; bráctea floral en forma de embudo, mucronata, que envuelve el pedicelo y a veces totalmente el ovario, 1.0-1.5 mm de largo; pedicelo $0.5-1.0 \mathrm{~mm}$ de largo; filamento $2.5 \mathrm{~mm}$ de largo; ovario $1 \mathrm{~mm}$ de largo. Flor no resupinada, perianto amarillo claro, eciliada, 


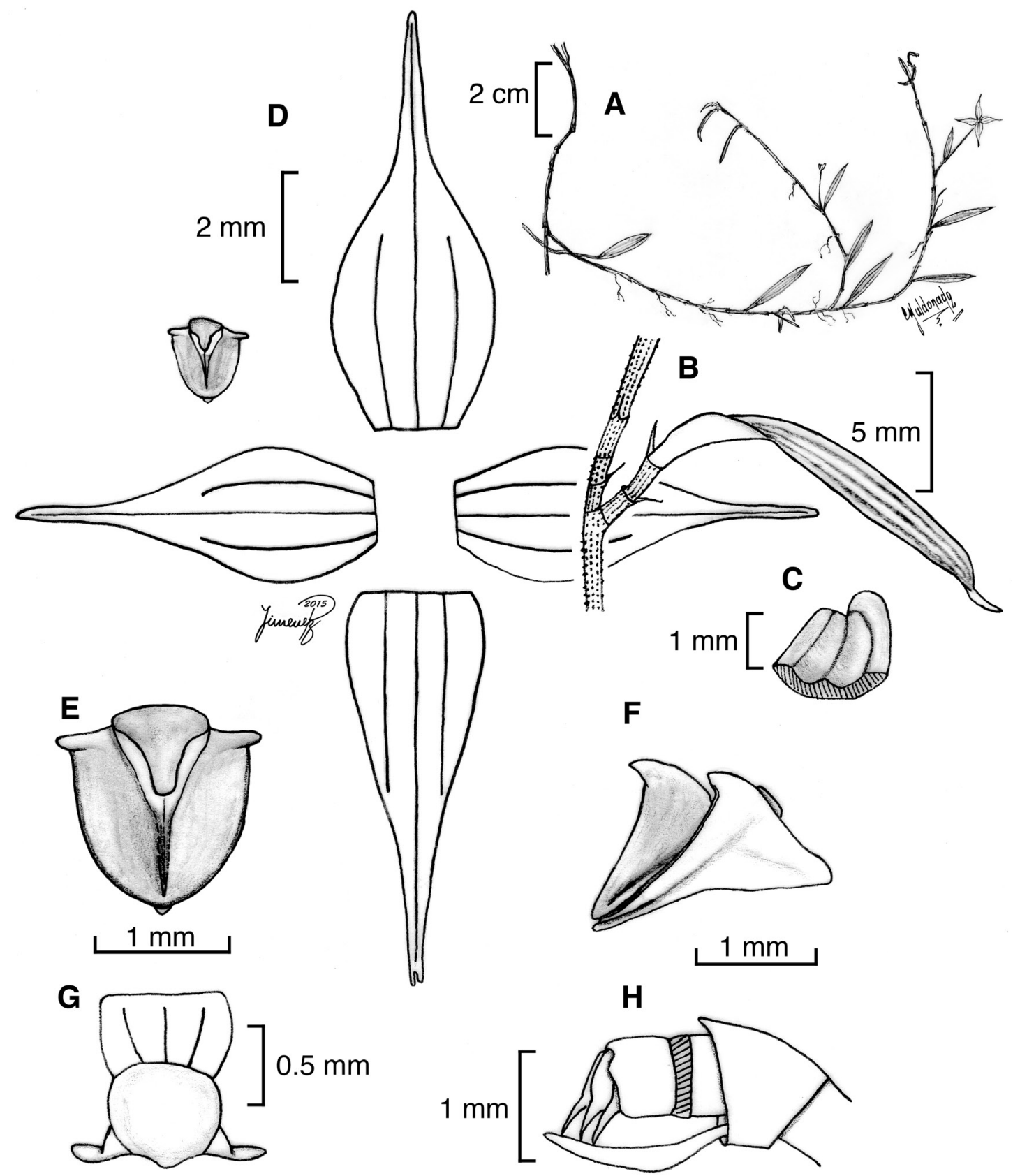

FiguRA 2. Brachionidium sulcatum. A. Hábito. B. Hoja vista lateral. C. Hoja corte transversal. D. Flor diseccionada. E. Labelo vista frontal. F. Labelo vista lateral. G. Labelo vista dorsal. H. Columna vista lateral. Dibujo a partir del holotipo de I. Jiménez Pérez y C. Maldonado.

con rayas longitudinales moradas, labelo amarillo claro pero morado en su cara exterior; sépalo dorsal ovado, agudo, $7.5 \times 3.0 \mathrm{~mm}$, de 3 venas, cortamente acuminado; sépalos laterales unidos en un sinsépalo lanceolado, agudo, $0.2 \mathrm{~mm}$ bífido en el ápice, $7.0 \times$ $2.5 \mathrm{~mm}$, de 4 venas, cortamente acuminado; pétalo ovado, ligeramente oblicuo, agudo, $6.5 \times 2.5 \mathrm{~mm}$, de 3 venas, cortamente acuminado; labelo ovado-oblongo 

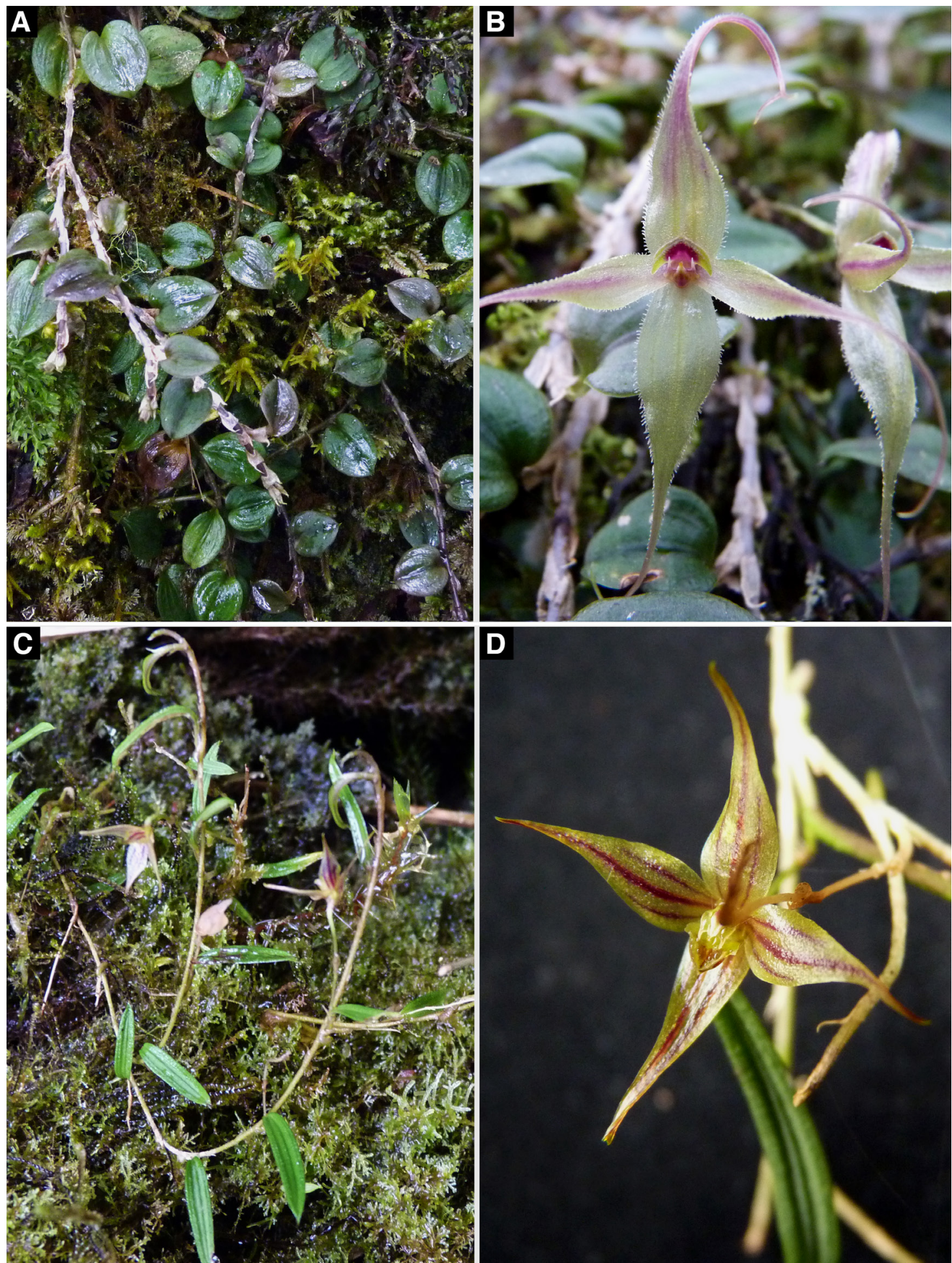

D

Figura 3. Brachionidium lopez-robertsiae. A. Hábito. B. Flor (ambas de I. Jiménez 5620). Brachionidium sulcatum. C. Hoja. D. Flor (ambas de I. Jiménez 5619). Fotografías de I. Jiménez Pérez. 
de frente, cóncavo, margen anterior bimarginado, cortamente submamilado, $1.5 \times 1.5 \mathrm{~mm}$ no expandido, apéndices laterales erguidos, agudos y antrorsos, disco con un callo subgloboso notorio, glenion en la cara anterior; columna recta, bidentada, $1.4 \mathrm{~mm}$ de largo; polinario no visto.

Distribución y eCOlogía: Especie conocida solo de la localidad tipo, al interior del PN-ANMI Cotapata, hallada en el bosque nublado de ceja de montaña. Crece en medio de vegetación herbácea y entremedio de colchones de musgo. Conocida de una pequeña población a $3387 \mathrm{~m}$. Florece en noviembre y diciembre.

Etimología: El nombre deriva del Latín sulcatus, sulcado, el cual hace referencia a los dos surcos que se observan en el haz de la hoja.

La combinación de un rizoma delgado, largamente rastrero, hojas estrechamente oblongas con dos surcos laterales en el haz diferencian B. sulcatum de cualquier otra especie conocida de Brachionidium. La única otra especie con hoja sulcada es B. Galeatum, pero ésta es rugosa a lo largo de las venas, elíptica y de rizoma erecto (Luer, 1995). Esta orquídea corresponde a una de las dos especies nuevas citadas en Vásquez et al. (2014).

\section{Lepanthopsis trulliformis I.Jiménez, sp. nov.}

TIPO: Bolivia. La Paz: Provincia Nor Yungas, Parque Nacional Cotapata, $67^{\circ} 52^{\prime} \mathrm{O}, 16^{\circ} 16^{\prime} \mathrm{S}, 3420$ m, 16 octubre 2006, I. Jiménez y F. Lipa 4146 (LPB) (holotipo: LPB; isotipo: BOLV). Figs. 4, 6A, 6B.

Lepanthopsis trulliformis differs from the other two similar species, L. apoda (Garay \& Dunst.) Luer and L. dewildei Luer \& Escobar, by the longer ramicauls (up to $9 \mathrm{~cm}$ ), and a flower with 2-veined lateral sepals, trullate and retrorse petals with a recurved apex, and a suborbiculate, obtuse and slightly incurved lip.

Hierba pequeña a mediana, epífita, cespitosa, hasta $11.7 \mathrm{~cm}$ de alto. Tallo retrorso a ascendente, 2.2-9.0 $\mathrm{cm}$ de largo, envuelto por (3-)4-6 vainas lepantiformes microscópicamente ciliadas, papiloso y espiculado a lo largo de las costillas. Hoja coriácea, ligeramente arcuada, verde oscuro maculado de morado o totalmente morado en el envés, envés verrucoso o glabro, oblonga o elíptica, bordes a veces irregularmente espiculadas, ápice agudo y engrosado, 9-32 × 1.5-7.0 mm, 2.0-
$2.5 \mathrm{~mm}$ de grosor, base cortamente cuneada, peciolo envuelto por la vaina, $2 \mathrm{~mm}$ de largo. Inflorescencia fasciculada, uniflora, floración continua, pedúnculo basalmente cubierto por una bráctea, $4 \mathrm{~mm}$ de largo; bráctea floral, infundibuliforme, oblicua, envuelve totalmente al pedicelo, $2.5 \mathrm{~mm}$ de largo; pedicelo 2.5 $\mathrm{mm}$ de largo, ovario $1 \mathrm{~mm}$ de largo. Flor de sépalos y pétalos morados o marrón morados con los bordes translucientes, labelo marrón morado u ocre, columna morada o verde, antera amarilla; sépalo dorsal ovado triangular, retrorso, ápice obtuso e incurvado en posición natural, $4.5-5.5 \times 2.3-2.4 \mathrm{~mm}$, de 3 venas, largamente acuminado; sépalos laterales ovados, oblicuos, ápices obtusos a veces incurvados generando puntas ligeramente convexas, $4.0-5.0 \times 2.0-2.5 \mathrm{~mm}$, de 2 venas, nervios centrales carinados, acuminados, connatos por la base $1 \mathrm{~mm}$; pétalo trulado, retrorso, ápice obtuso, $4.5-5.0 \times 1.5-1.8 \mathrm{~mm}$, de 1 vena, largamente acuminado; labelo suborbicular, ápice obtuso y ligeramente incurvado, $2.5 \times 1.5-2.0 \mathrm{~mm}$, de 3 venas, unido a la base de la columna, basalmente con amplias aurículas erectas que envuelven a la columna, disco con una costilla transversal en la base; columna terete, $0.8 \mathrm{~mm}$ de largo, antera y estigma apicales; polinario no visto.

Paratipos: Bolivia. La Paz: Nor Yungas, Parque Nacional Cotapata, sendero Chojllapata, $67^{\circ} 52^{\prime} \mathrm{O}$, $16^{\circ} 16^{\prime} \mathrm{S}, 3400 \mathrm{~m}, 27$ diciembre 2005, I. Jiménez et al. 3586 (LPB); ibid, $67^{\circ} 52^{\prime} \mathrm{O}, 16^{\circ} 15^{\prime} \mathrm{S}, 3250 \mathrm{~m}, 18$ noviembre 2005, F. Miranda et al. 1005 (LPB). Perú. Huancavelica: Tayacaja, Huachocolpa, 2800-3400 m, 9 julio 1999, M. León et al. 3034 (MOL).

DistribuCiÓn y eCología: Especie andina distribuida desde el centro sur del Perú hasta el oeste de Bolivia, en laderas y crestas del bosque nublado de la cordillera de los Andes. Crece generalmente en la zona ventral de ramas de pequeños árboles remanentes, donde a veces forma poblaciones densas. Se distribuye de 2800-3400 m. Florece todo el año.

Etimología: El nombre específico deriva del Latín trulliformis, trulado, en referencia a la forma romboidal de los pétalos.

En Bolivia, L. trulliformis habita por encima de los $3200 \mathrm{~m}$ de elevación, posee tallos de hasta $9 \mathrm{~cm}$ de largo, flor morada, sépalos laterales de 2 venas, 


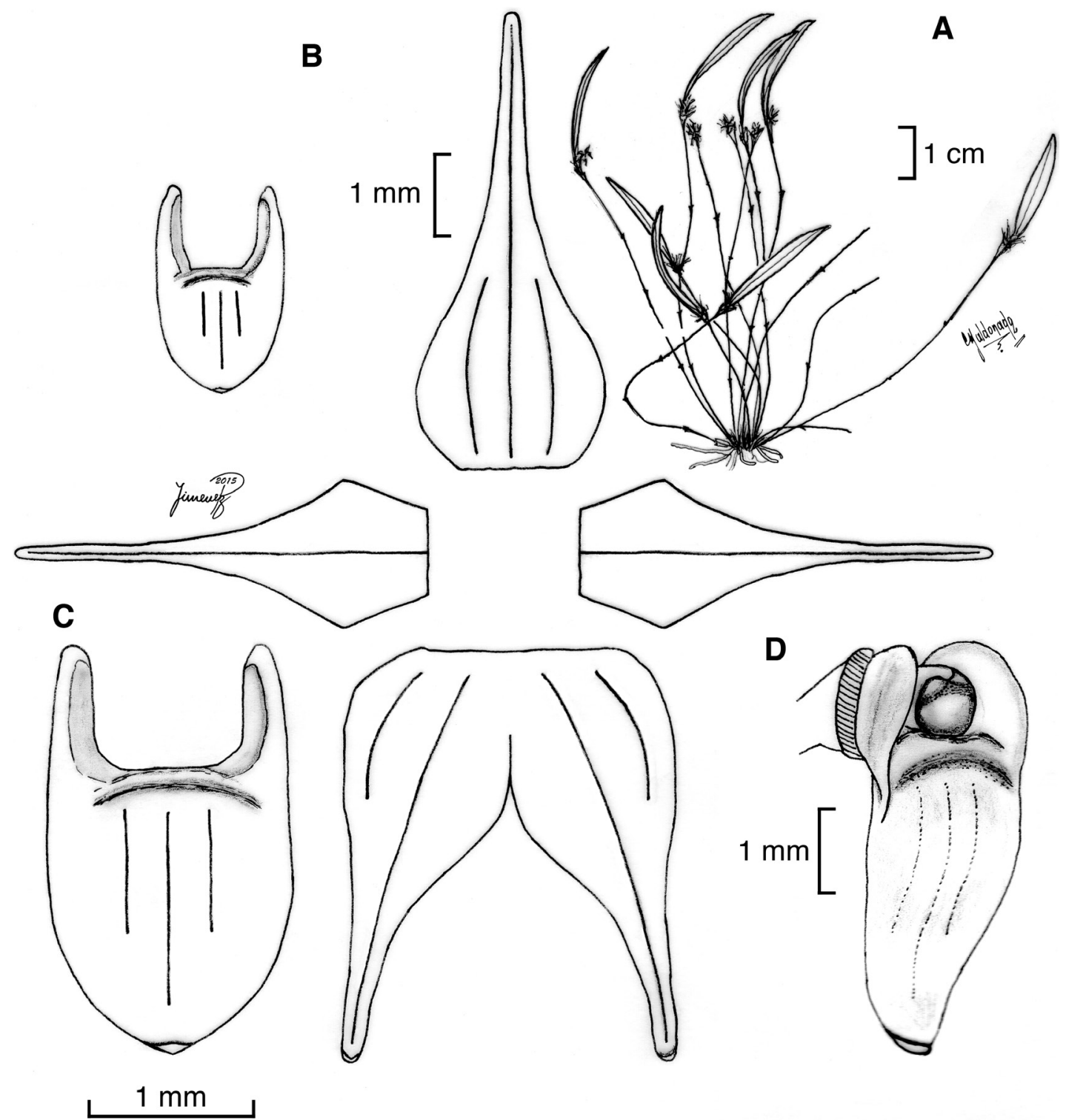

Figura 4. Lepanthopsis trulliformis. A. Hábito. B. Flor diseccionada. C. Labelo vista frontal. D. Columna y labelo, vista lateral. Dibujo a partir del holotipo de I. Jiménez Pérez y C. Maldonado.

aunque connatos no son cóncavos, pétalos trulados y labelo suborbicular con ápice obtuso y ligeramente incurvado. Una especie similar que habita en la misma región es $L$. apoda, especie de amplia distribución, con inflorescencia uniflora, pero a diferencia de la primera, en Bolivia se encuentra en elevaciones medias, 14002600 m (Vásquez \& Ibisch 2000), la planta es más pequeña (tallos de hasta $5 \mathrm{~cm}$ de largo), la flor amarilla, los sépalos laterales con 1 vena, connatos, que forman un sinsépalo cóncavo y pétalos ovados (Figs. 6C, 6D). Morfológicamente es más similar a $L$. dewildei, pero se diferencia de ésta por tener hojas mas delgadas, 1.5-4.5 $\mathrm{mm}$ (vs 5-6 mm), ápice de los sépalos incurvados (vs ápices planos) y pétalos trulados y retrorsos (vs pétalos ovados y no retrorsos). La principal diferencia con la muestra peruana es que tiene hojas elípticas más cortas y más anchas (15-20 x 3-7 mm), sépalos mas cortos (4.0$4.5 \mathrm{~mm}$ ), labelo ocre y crece por debajo los $3200 \mathrm{~m}$. 


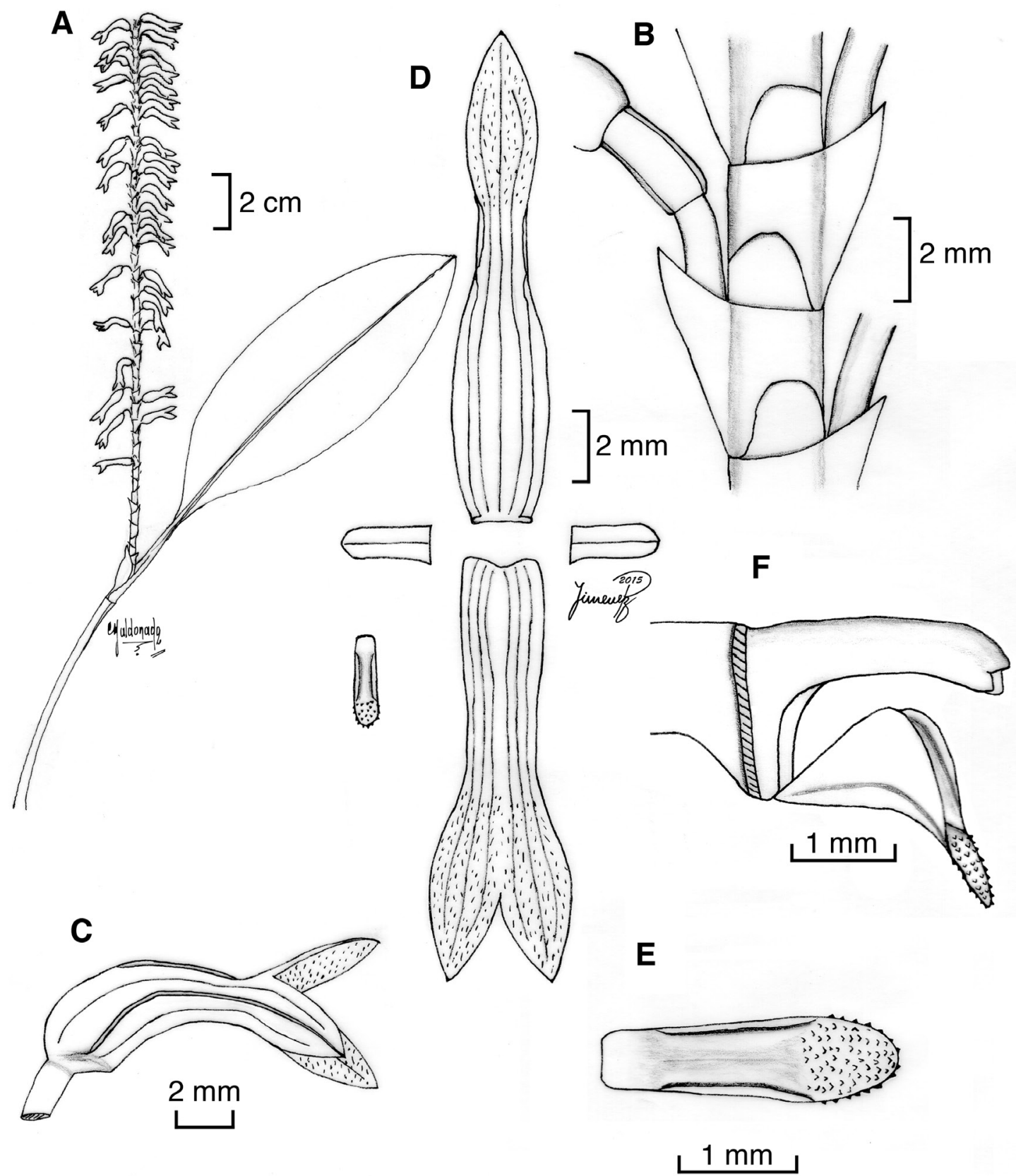

Figura 5. Stelis pertusa. A. Hábito. B. Brácteas florales. C. Flor vista lateral. D. Flor diseccionada. E. Labelo vista dorsal. F. Columna y labelo, vista lateral. Dibujo a partir del holotipo de I. Jiménez Pérez y C. Maldonado.

La inflorescencia puede tener hasta dos flores abiertas simultáneamente (B. Collantes, com. pers. 2015). Fue erróneamente identificada como Lepanthopsis apoda por Bennett \& Christenson (2001). Esta orquídea es señalada como Expedicula Luer especie nueva en Vásquez et al. (2014).
Stelis pertusa I.Jiménez, sp. nov.

TIPO: Bolivia. La Paz: Provincia Franz Tamayo, Parque Nacional Madidi, Sumpulo, cruzando el río

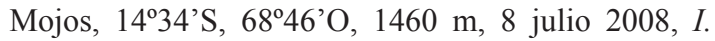
Jiménez 5404 (holotipo: LPB). Fig. 5, 7, 8. 

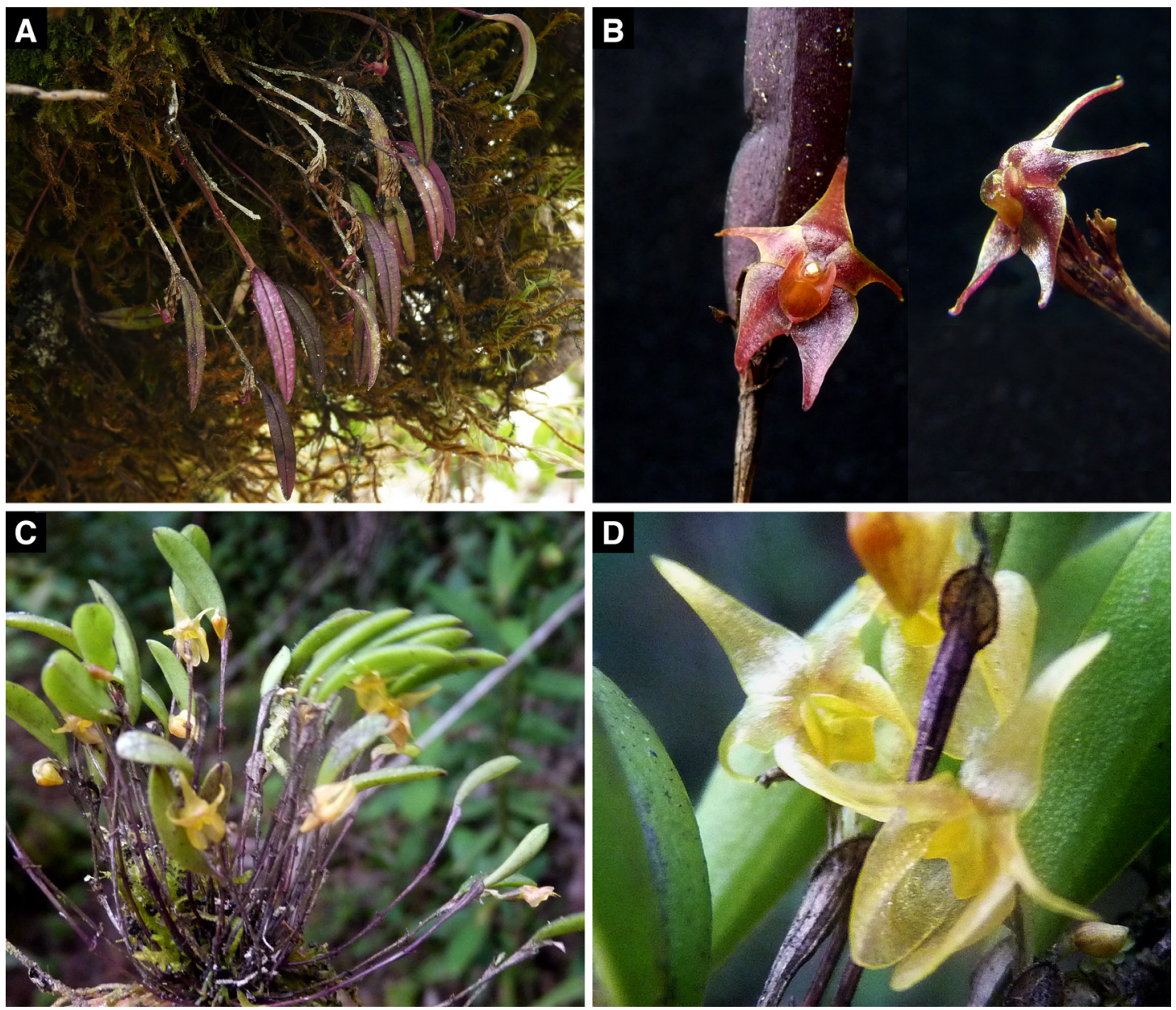

Figura 6. Lepanthopsis trulliformis. A. Hábito. B. Flor. Lepanthopsis apoda. C. Hábito. D. Flor (ambas de I. Jiménez 6233). Fotografías de I. Jiménez Pérez.

Stelis pertusa differs from all others species of Stelis with connate sepals by a distichous inflorescence, floral bracts with a notch on the basal margin, flowers with the inner surface of the free lobe of the sepals hirsutulous, oblong petals, lip with a spiculate midlobe, and a completely alate column.

Hierba mediana, epífita, cespitosa, $28 \mathrm{~cm}$ de alto aproximadamente. Tallo erecto, unifoliado, $11.5 \mathrm{~cm}$ de largo, envuelto por 1 vaina situada abajo del medio. Hoja erecta, coriácea, lisa, angostamente elíptica, obtusa, $13.9 \times 4.5 \mathrm{~mm}$, base cuneada, pecíolo $3.1 \mathrm{~mm}$ de largo. Inflorescencia un racimo solitario, erecta, multiflora, dística, $19.5 \mathrm{~cm}$ de largo, pedúnculo 13 $\mathrm{mm}$ de largo; bráctea floral, oblicua, con una muesca sobre el lado más corto, que abarca ambas caras,
$5 \mathrm{~mm}$ el lado más largo; pedicelo $6 \mathrm{~mm}$ de largo; ovario carinado, $2.5 \mathrm{~mm}$ de largo. Flor de perianto y ginostemo amarillo claro, aroma dulce, sépalos connatos que forman un tubo sepalino desde los 2 tercios hacia la base, constricto por debajo de las partes libres, éstos densamente hírtulos por dentro, nervios centrales carinados prolongándose a todo el largo del tubo sepalino; sépalo dorsal elíptico en su parte libre, apiculado, $14 \times 2 \mathrm{~mm}$, de 3 venas, connato a los sépalos laterales $9 \mathrm{~mm}$; sépalos laterales elípticos en su parte libre, apiculados, $12.0 \times 2.2 \mathrm{~mm}$, de 3 venas, connatos $7 \mathrm{~mm}$; pétalo oblongo, ápice obtuso, $2.5 \times 0.9 \mathrm{~mm}$, de 1 vena; labelo estrechamente obovado, arcuado, ápice obtuso y espiculado, trilobulado en extensión, $2.5 \times 0.7$ $\mathrm{mm}$ sin expandir, de 3 venas, carinado a lo largo de las 


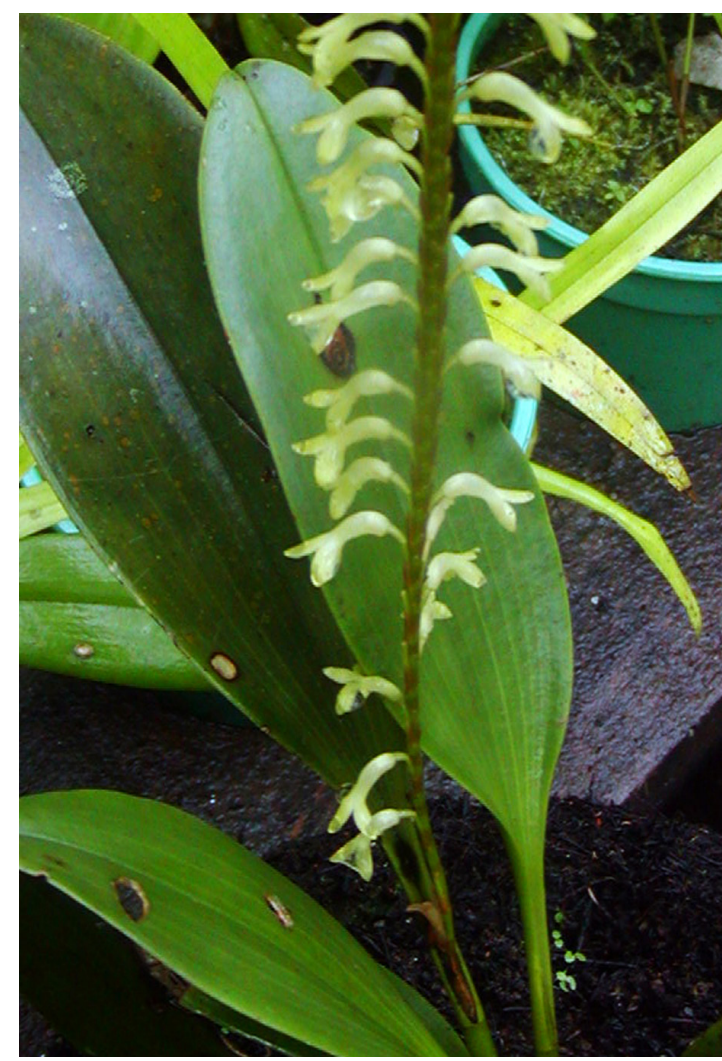

Figura 7. Hábito de Stelis pertusa (I. Jiménez 5404). Fotografía de M. López.

venas, lóbulos laterales subdeltoides, erectos, obtusos, flanqueados por una cresta paralela a los lóbulos, base truncada, articulado al pie de la columna; columna semiterete, alada, $2.7 \mathrm{~mm}$ de largo, pie $1 \mathrm{~mm}$ de largo, antera y estigma ventrales; polinario no visto.

DistriBuCión y eCOlOGíA: Hallada en el noroeste del departamento de La Paz, en bosque montano estacionalmente húmedo del Parque Nacional Madidi. Este especie representa la distribución más austral de este grupo de orquídeas. Habita bosques de 20 a $25 \mathrm{~m}$ de alto, con sotobosque denso, abundantes lianas y piso con mucha hojarasca. Solo se encontró un individuo. Conocida por el momento solo de la localidad tipo a 1460 m. Floreció en cultivo en marzo y abril del 2009.

Etimología: El nombre deriva del Latín pertusus = perforado, en referencia a la muesca que poseen las brácteas florales.

A simple vista la principal diferencia de Stelis pertusa con las otras 4 especies de este género que

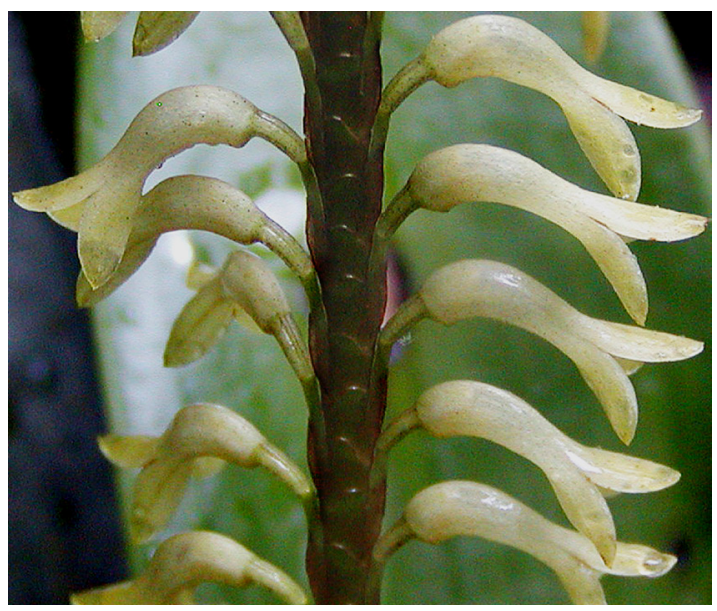

FIGURA 8. Brácteas florales y flores de Stelis pertusa (I. Jiménez 5404). Fotografía de M. López.

poseen sépalos connatos es la disposición de las flores, en la primera es dística y en las otras es secunda. Otros rasgos que la identifican son: brácteas florales con una muesca, lóbulos libres de los sépalos interiormente hírtulos, pétalos oblongos, lóbulo medio del labelo espiculado y columna totalmente alada. En S. asperrima del Ecuador, los sépalos interiormente son pubescentes y los pétalos son oblongos, sin embargo, el lóbulo medio del labelo es agudo y bicarinado. Las otras especies aunque en mayor o menor grado poseen el lóbulo medio del labelo verrucoso o glandular-papiloso, todas poseen pétalos obovados < a $2 \mathrm{~mm}$ y sépalos interiormente glabros, excepto $S$. tacanensis que es pubescente pero en la parte media de los sépalos connatos y columna alada solo en la mitad superior. Sin embargo, ninguna de las especies afines poseen brácteas florales con muescas. Esta orquídea es indicada como Physosiphon Lindl. especie nueva en Vásquez et al. (2014).

\section{Trichosalpinx adnata I.Jiménez, sp. nov.}

TIPO: Bolivia. La Paz: Provincia Nor Yungas, Parque Nacional Cotapata, $67^{\circ} 53^{\prime} \mathrm{O}, 16^{\circ} 17^{\prime} \mathrm{S}, 3458 \mathrm{~m}, 26$ marzo 2011, I. Jiménez 5624 (holotipo: LPB; isotipo: BOLV, HSB, USZ). Figs. 9, 12A, 12B.

Morphologically Trichosalpinx adnata is similar to the sympatric $T$. chamaelepanthes (Rchb.f.) Luer but differs in the lip with short lateral lobes and a slightly furrowed disc and the column-foot adnate to the concave base of the laterals sepals

Hierba pequeña, epífita y terrestre sobre gruesas 


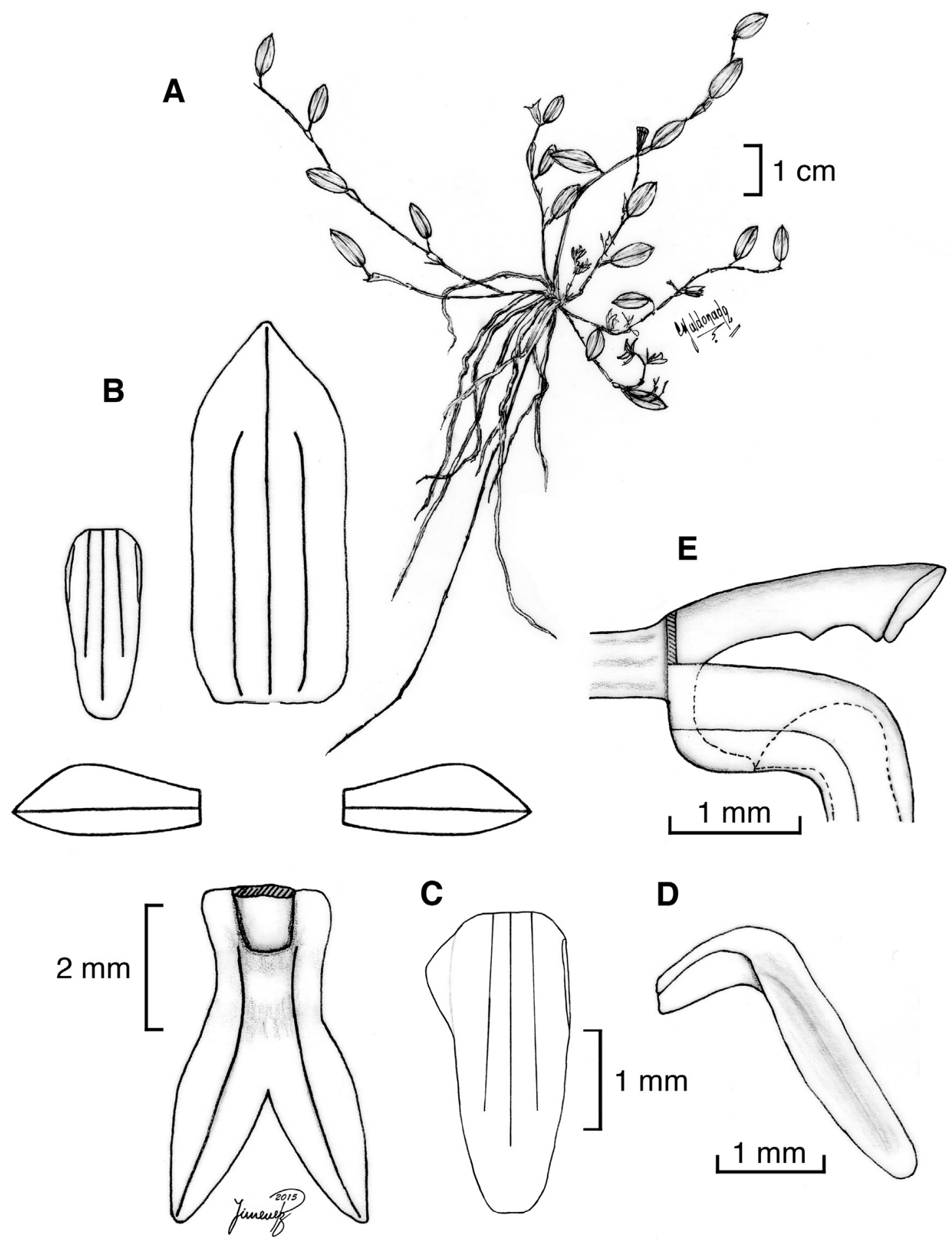

Figura 9. Trichosalpinx adnata. A. Hábito. B. Flor diseccionada. C. Labelo vista dorsal. D. Labelo vista lateral. E. Columna y sépalo lateral, vista lateral. Dibujo a partir del holotipo de I. Jiménez Pérez y C. Maldonado. 
capas de musgo, cespitosa, hasta $12.5 \mathrm{~cm}$ de alto. Tallo ascendente, prolífico, (1.0-)1.2-7.0(-9.3) cm de largo, envuelto por 3-6(-7) vainas lepantiformes microscópicamente ciliadas. Hoja erecta, coriácea, oblonga-elíptica, obtusa, papiloso al final de la vena media, $6-18 \times 3.5-6.0(-7.0) \mathrm{mm}$, base cortamente cuneada, pecíolo sulcado, $0.5-10.0 \mathrm{~mm}$ de largo. Inflorescencia racemosa, pauciflora, flexuosa, con hasta 3 flores, 1 a 3 flores abiertas simultáneamente, $0.5-1.5 \mathrm{~cm}$ de largo, pedúnculo con 1 o 2 brácteas, 1-6 $\mathrm{mm}$ de largo; bráctea floral infundibuliforme, $1.0-1.5 \mathrm{~mm}$ de largo; pedicelo cubierto parcial o totalmente por la bráctea, $1.5 \mathrm{~mm}$ de largo; ovario levemente sulcado, $0.5 \mathrm{~mm}$ de largo. Flor de sépalos y pétalos tenuemente amarillo o blanco translúcido, con 1 a 3 rayas longitudinales tenuemente moradas, labelo morado, bordes claros, columna amarilla clara, sépalos carinados; sépalo dorsal oblongo, cóncavo, ápice obtuso, $5.0-6.0 \times 2.5 \mathrm{~mm}$, de 3 venas; sépalos laterales oblongos, cóncavos en la base, ápices obtusos, recurvados, 5.0-5.5 × $1.4 \mathrm{~mm}$, de 1 vena, connatos 1.5$2.0 \mathrm{~mm}$, formando un mento con el pie de la columna; pétalo elíptico-obovado, ápice agudo, oblicuo, 2-3 × 1 $\mathrm{mm}$, de 1 vena; labelo ovado-oblongo, ápice obtuso, trilobulado en extensión, $3.0 \times 1.2 \mathrm{~mm}$ no expandido, de 3 venas, lóbulos laterales erectos, cortos, suborbicular, disco ligeramente sulcado, base truncada, articulado al pie de la columna; columna terete, el ápice con un par de dientes cónicos, obtusos, retrorsos, 1.5-2.0 $\mathrm{mm}$ de largo, pie de la columna adnato a la base de los sépalos laterales, $1 \mathrm{~mm}$ de largo, antera subapical, estigma ventral; polinios un par.

Paratipo: Bolivia. La Paz: Nor Yungas, Parque Nacional Cotapata, sendero Chojllapata, 6752'O, $16^{\circ} 16^{\prime}$ S, 3294 m, 22 octubre 2010, I. Jiménez 5605 (LPB).

DistribuCiÓn y eCOLOGíA: Hallada al interior del PN-ANMI Cotapata, en el bosque nublado de ceja de montaña. Puede formar poblaciones densas en la base del tronco o de pocos individuos colgados en las ramas. Se distribuye entre 3200-3400 m. Florece en octubre, febrero y marzo.

Etimología: El nombre deriva del Latín adnatus, adnato, en referencia al pie de la columna que es adnato a la base de los sépalos laterales.
Trichosalpinx adnata pertenece al subgénero Tubella Luer, se caracteriza por ser pauciflora, con 1 a 3 flores por inflorescencia, el sépalo dorsal casi tan ancho como los sépalos laterales juntos, el labelo con lóbulos laterales cortos y el disco ligeramente sulcado y el pie de la columna adnato a la base cóncava de los sépalos laterales. En la misma zona crece $T$. chamaelepanthes, especie ampliamente difundida en los Andes, a la cual se parece por tener tallos prolíficos, hojas elípticas, inflorescencia pauciflora y sépalo dorsal ancho; sin embargo, esta última se diferencia de T. adnata por tener sépalos equinados en los márgenes (vs. sépalos no equinados), pie de la columna adnato a la base de los sépalos laterales (vs pie de la columna libre) y labelo ligeramente cóncavo (vs. labelo ligeramente sulcado). Esta orquídea corresponde a una de las cuatro especies nuevas citadas en Vásquez et al. (2014).

\section{Trichosalpinx gabi-villegasiae I.Jiménez, sp. nov.}

TIPO: Bolivia. La Paz: Provincia Nor Yungas, Parque Nacional Cotapata, sendero Chojllapata, 67'52'O, 16²'S, 3435 m, 15 agosto 2009, I. Jiménez et al. 5500 (holotipo: LPB). Figs. 10, 13, 14.

Trichosalpinx gabi-villegasiae is related to $T$. tenuis (C.Schweinf.) Luer but differs in the pendent multiflowered inflorescence, the dorsal sepal with recurved apex, the patent lateral sepals, the ligulate lip with a reflexed apex and the disc with a pair of low crests.

Hierba pequeña, epífita, cespitosa, hasta $10 \mathrm{~cm}$ de longitud. Tallo erecto, $1.7-5.4 \mathrm{~cm}$ de largo, envuelto por 3-5 vainas lepantiformes microscópicamente ciliadas. Hoja erecta, coriácea, elíptica-oblonga, apiculada, 18-40 $\times$ 5-8 mm, base cortamente cuneada, peciolo sulcado, 1-2 mm de largo. Inflorescencia racemosa, multiflora, péndula, laxa, con 5-9 flores abiertas simultáneamente, 3.5-8.1 cm de largo, pedúnculo con 3 brácteas, 12-25 $\mathrm{mm}$ de largo; bráctea floral infundibuliforme, oblicua, 2 $\mathrm{mm}$ de largo; pedicelo 3-6 $\mathrm{mm}$ de largo; ovario $1 \mathrm{~mm}$ de largo. Flor de perianto y ginostemo amarillo claro a amarillo verdoso, sépalos carinados; sépalo dorsal ovado-oblongo, cóncavo, ápice agudo, notoriamente recurvado, $8 \times 2 \mathrm{~mm}$, de 3 venas, nervios laterales finos, acuminado; sépalos laterales patentes, angostamente triangular atenuados, falcados y divaricados, ápice agudo, 


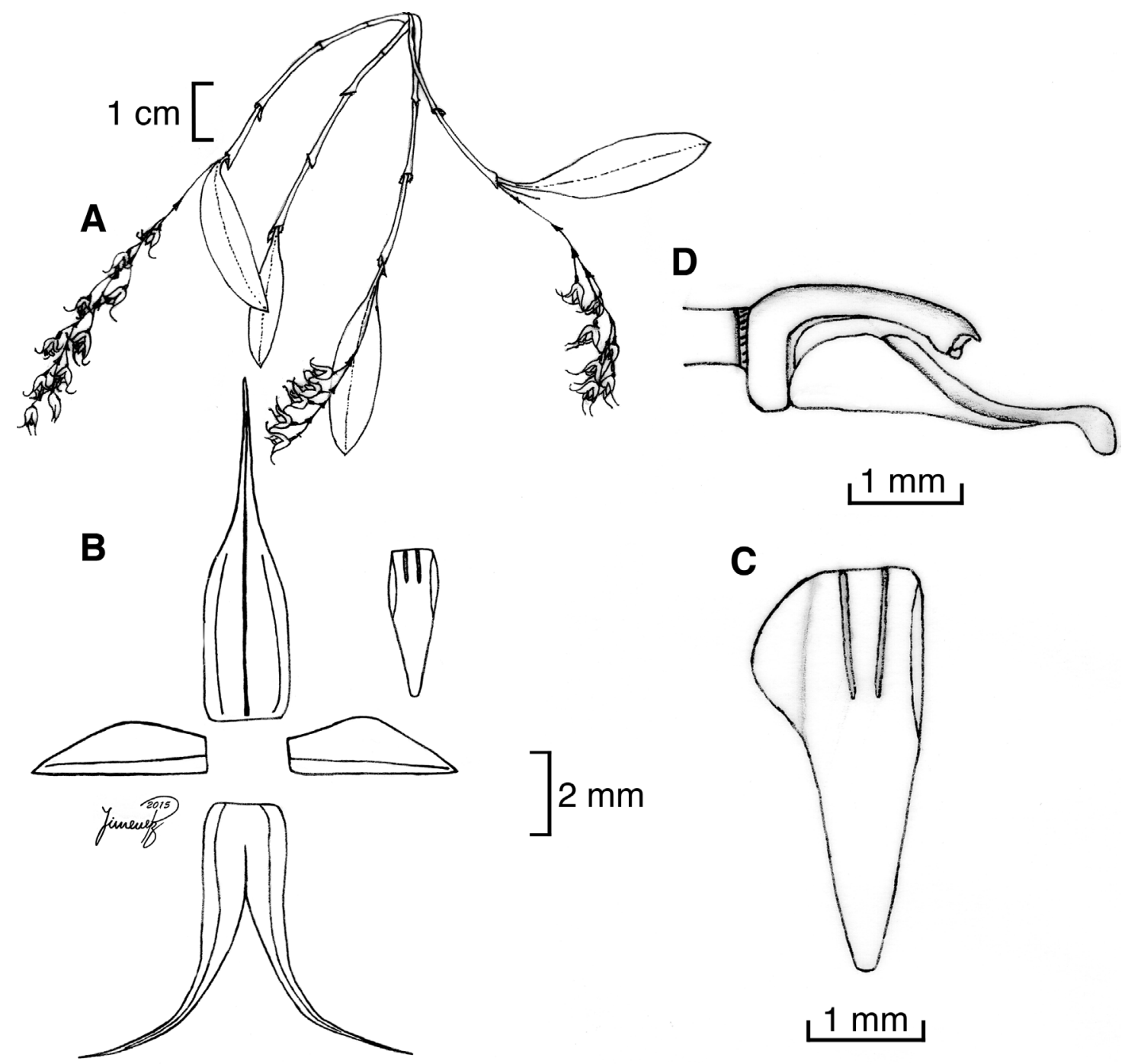

Figura 10. Trichosalpinx gabi-villegasii. A. Hábito. B. Flor diseccionada. C. Labelo vista dorsal D. Columna y labelo, vista lateral. Dibujo a partir del holotipo de I. Jiménez Pérez.

ligeramente recurvados, $8 \times 2 \mathrm{~mm}$, de 1 vena, connatos 2.5 $\mathrm{mm}$; pétalo elíptico, ápice agudo, oblicuo, $4.0 \times 1.3 \mathrm{~mm}$, de 1 vena; labelo lingüiforme oblongo-triangular, ápice subagudo, reflexo, trilobulado en extensión, $3 \times 1 \mathrm{~mm}$ no expandido, lóbulos laterales erectos, suborbiculares, disco basalmente con un par de costillas longitudinales, base truncada, articulado al pie de la columna; columna terete, $2 \mathrm{~mm}$ de largo, pie $0.5 \mathrm{~mm}$ de largo, antera y estigma ventrales; polinario no visto.

Paratipo: Bolivia. La Paz: Nor Yungas, Parque Nacional Cotapata, sendero Chojllapata, $67^{\circ} 52^{\prime} \mathrm{O}, 16^{\circ} 16^{\prime} \mathrm{S}, 3430$ m, 18 septiembre 2010, I. Jiménez 5601 (LPB).

Distribución y eCOlogía: Encontrada al interior del PN-ANMI Cotapata, en el bosque nublado de ceja de montaña. Crece en el tronco y ramas de árboles pequeños, no mayores a $5 \mathrm{~m}$. Solo se conocen dos pequeñas poblaciones situadas en el rango de $3400 \mathrm{~m}$. Florece en marzo-abril y agosto-septiembre.

Etimología: Esta orquídea se dedica a Gabriela (Gabi) Villegas Alvarado, amiga y colega que alentó y acompañó animadamente muchos viajes a la zona 


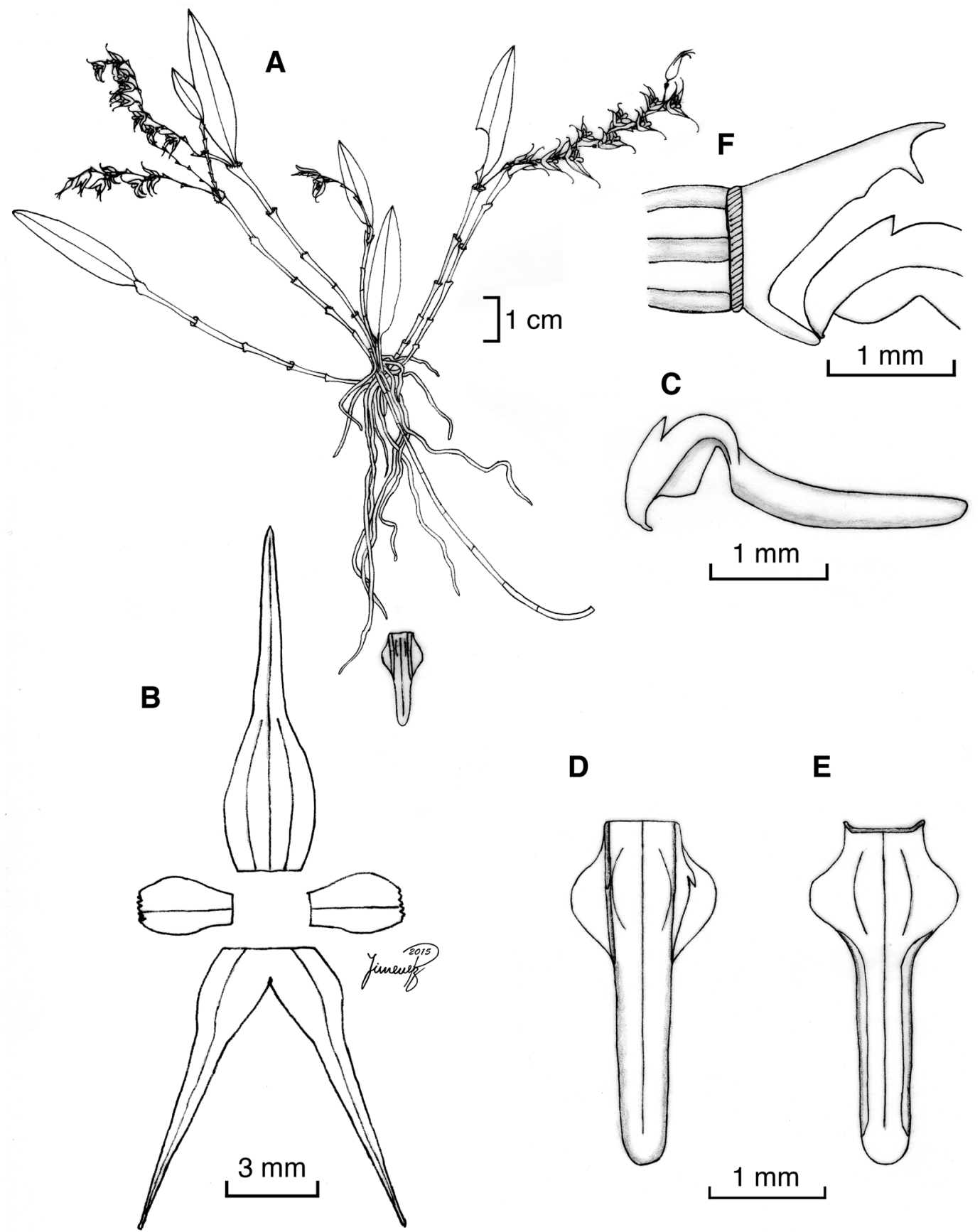

Figura 11. Trichosalpinx giovi-mendietae. A. Hábito. B. Flor diseccionada. C. Labelo vista lateral. D. Labelo vista dorsal.

E. Labelo vista ventral. F. Columna y labelo, vista lateral. Dibujo a partir del holotipo de I. Jiménez Pérez.

de estudio, además de ser una de las propiciadoras del proyecto que inicio el estudio de orquídeas y otras epífitas en el PN-ANMI Cotapata.

Trichosalpinx gabi-villegasiae pertenece al subgénero Tubella, se caracteriza por llevar una inflorescencia multiflora péndula, sépalos laterales patentes, sépalo dorsal con ápice notoriamente recurvado, labelo ligulado con un par de crestas 

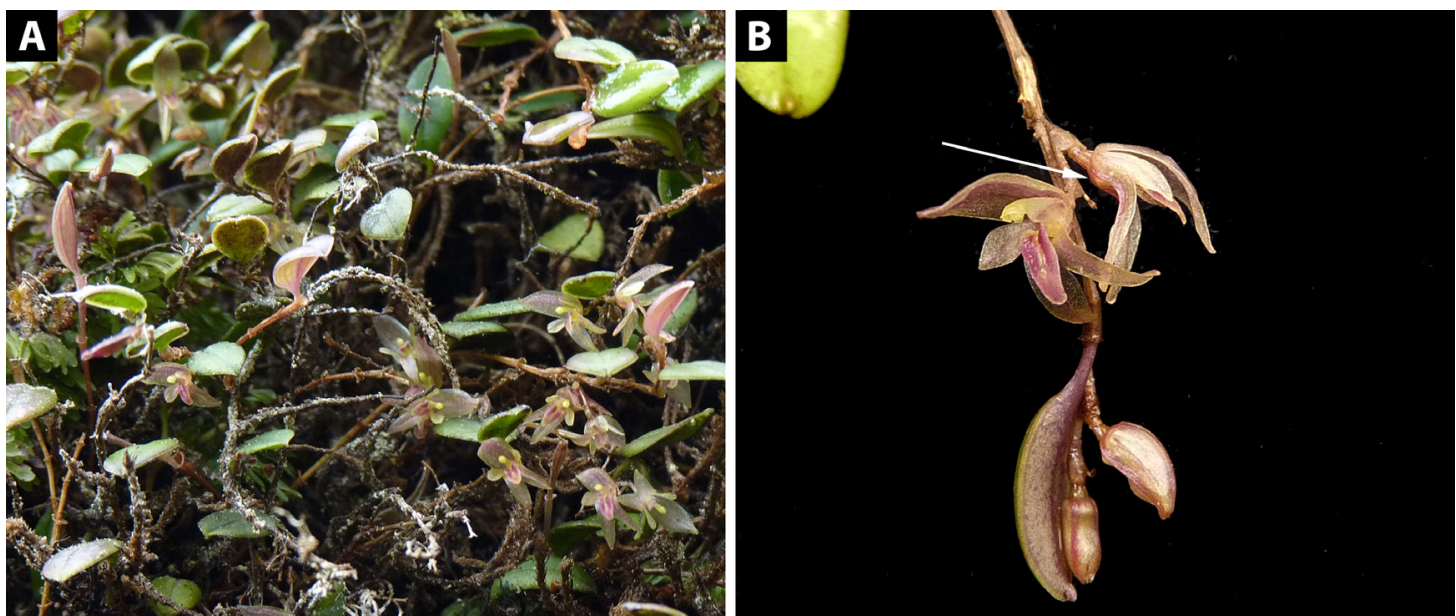

Figura 12. Trichosalpinx adnata. A. Hábito (I. Jiménez 5624). B. Flor, la flecha indica la ubicación del mento (I. Jiménez

5605). Fotografías de I. Jiménez Pérez.

longitudinales y ápice reflexo. Con T. tenuis comparten rasgos como: sépalos carinados, sépalos laterales angostamente triangulares, ápice agudo y atenuado, pétalos elípticos, oblicuos y agudos y labelo lingüiforme (Luer, 1997), pero la inflorescencia es suberecta y secunda y el labelo arriba de la base posee un callo longitudinalmente hendido. Otra especie relacionada es T. ligulata Luer \& Hirtz que también posee un labelo lingüiforme, sin embargo, no tiene costillas ni el ápice reflexo, además la inflorescencia es pauciflora y erecta y los sépalos laterales no son patentes. Esta orquídea corresponde a una de las cuatro especies nuevas citadas en Vásquez et al. (2014).

\section{Trichosalpinx giovi-mendietae I.Jiménez, sp. nov.}

TIPO: Bolivia. La Paz: Provincia Nor Yungas, Parque Nacional Cotapata, sendero Chojllapata, 67 $52^{\prime} \mathrm{O}$, $16^{\circ} 16^{\prime}$ S, 3333 m, 26 febrero 2010, I. Jiménez 5623 (holotipo: LPB; isotipo: BOLV). Figs. 11, 15A-B.

Trichosalpinx giovi-mendietae is similar to T. dirhamphis (Luer) Luer but differs in having a trilobulate labellum with patents and rounded lateral lobes, the base of the labellum with a pair of crests ending in small antrorse tooth and a column with ligulate clinandrium.

Hierba mediana, epífita y terrestre sobre gruesas capas de musgo, cespitosa, hasta $21.5 \mathrm{~cm}$ de alto. Tallo ascendente, a veces prolíficos, $1.4-12.5 \mathrm{~cm}$ de largo, envuelto por 4-9 vainas lepantiformes

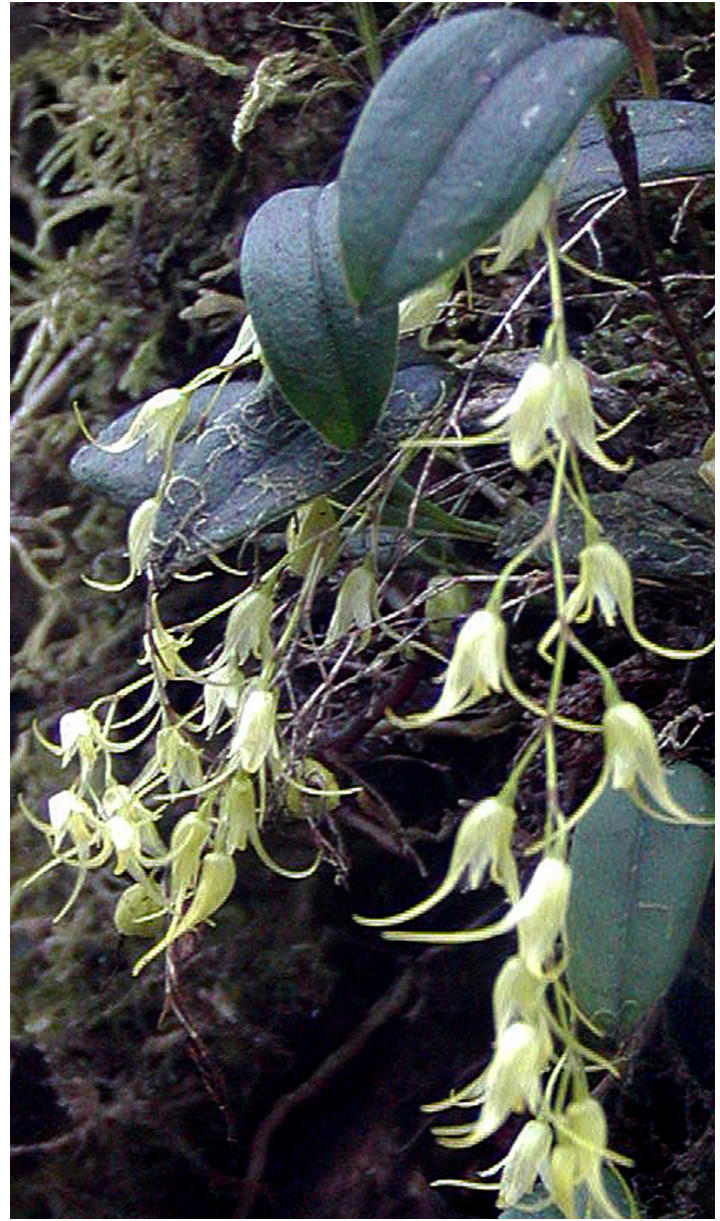

FIgURA 13. Hábito de Trichosalpinx gabi-villegasii (I. Jiménez 5500). Fotografía de I. Jiménez Pérez. 
microscópicamente ciliadas. Hoja erecta, coriácea, oblonga-lanceolada, apiculada, carinada en la base y el ápice, 12-41 × 4.5-9.0 mm, base cortamente cuneada, pecíolo sulcado, 1-3 $\mathrm{mm}$ de largo. Inflorescencia racemosa, multiflora, laxa, con 5-9(-10) flores abiertas simultáneamente, $1.7-5.7 \mathrm{~cm}$ de largo, pedúnculo 2-12 $\mathrm{mm}$ de largo; bráctea floral infundibuliforme, oblicua, 2.0-2.5 mm de largo; pedicelo 1.0-1.5 mm de largo, ovario $1 \mathrm{~mm}$ de largo. Flor de sépalos y pétalos amarillos, labelo rojo oscuro sobretodo al medio y en los lóbulos laterales al igual que los bordes de la columna, sépalos carinados; sépalo dorsal ovado, cóncavo. ápice agudo, $11 \times 3 \mathrm{~mm}$, de 3 venas, largamente acuminado; sépalos laterales ovado triangular, atenuados, ápice agudo, $8.5-9.5 \times 1.5 \mathrm{~mm}$, de 1 vena, connatos $1 \mathrm{~mm}$; pétalo obovado, oblicuo, ápice truncado, borde eroso, $3.0 \times 1.9$ $\mathrm{mm}$, de 1 vena; labelo ovado-oblongo, con los márgenes laterales revolutos o recurvados mas allá de los lóbulos laterales, ápice obtuso, trilobulado, $3.0 \times 1.3-1.5 \mathrm{~mm}$, de 1 vena, lóbulos laterales cortos, patentes, obtusos, flanqueado por un par de crestas erectas, obtusas, cada una basalmente lleva un diente antrorso, base truncada, articulado al pie de la columna; columna terete en la mitad distal y luego va engrosándose gradualmente hacia la base, clinandrio ligulado, $1.6 \mathrm{~mm}$ de largo, pie $0.5 \mathrm{~mm}$ de largo, antera y estigma ventrales, rostelo ligulado, retrorso, amarillento; polinario no visto.

Paratipo: BOliVia. La Paz: Nor Yungas, Parque Nacional Cotapata, $67^{\circ} 51^{\prime} \mathrm{O}, 16^{\circ} 16^{\prime} \mathrm{S}, 3000 \mathrm{~m}, 9$ enero 2010, I. Jiménez et al. 5528 (LPB).

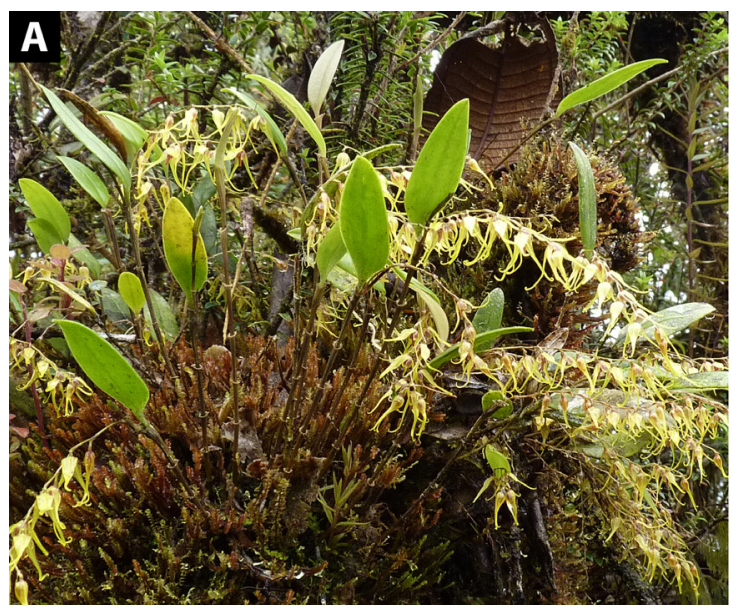

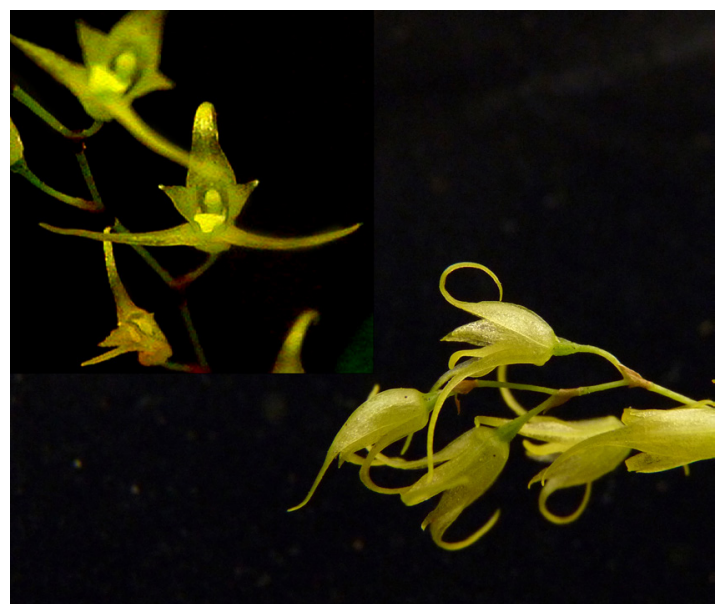

FIgURA 14. Flor de Trichosalpinx gabi-villegasii (I. Jiménez 5500). Fotografía de I. Jiménez Pérez.

Distribución y eCOlogía: Especie distribuida dentro el PN-ANMI Cotapata, en el bosque nublado de ceja de montaña y franja superior del bosque montano pluviestacional. Crece terrestre entre vegetación secundaria y epífito en árboles remanentes o bosque poco perturbado, donde puede formar poblaciones densas o de pocos individuos. Se la encuentra entre 2800-3400 m. Florece de enero a marzo.

Etimología: Se dedica esta especie a la bióloga Geovanna (Giovi) Mendieta†, amiga y compañera de estudios, a quien recordamos con gran cariño.

Trichosalpinx giovi-mendietae pertenece al subgénero Tubella, posee un rasgo que la distingue

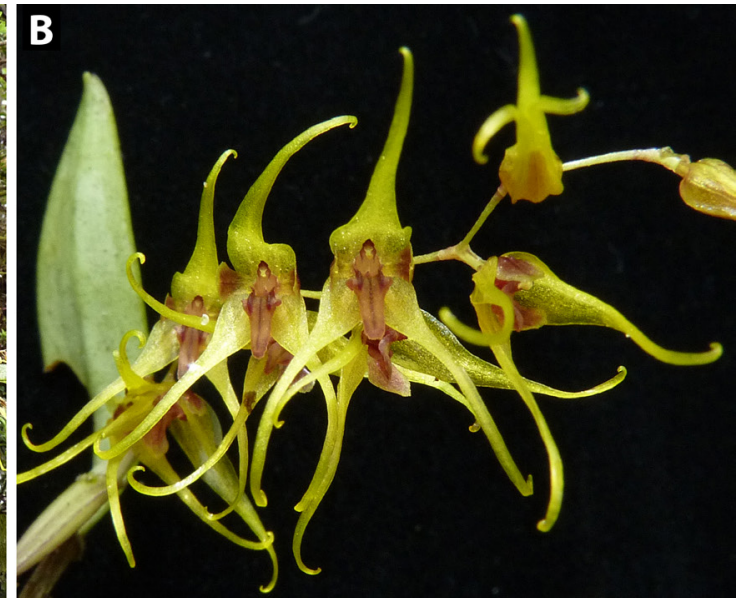

FIGURA 15. Trichosalpinx giovi-mendietae. A. Hábito. B. Flor, la flecha muestra la ubicación del clinandrio y rostelo (ambas de I. Jiménez 5623). Fotografías de I. Jiménez Pérez. 
claramente de la mayoría de las otras especies, el labelo tiene un par de crestas, cada una con un pequeño diente antrorso. La única otra especie que tiene un rasgo similar es T. quitensis (Rchb.f.) Luer, sin embargo, la inflorescencia es pauciflora (vs. multiflora), sépalos cortamente acuminados (vs. largamente acuminados), pétalos obtusos (vs. truncados), labelo amarillo claro, ovoide, margen no revoluto, 2.0-2.5 mm de largo (vs. labelo rojo oscuro, ovado-oblongo, margen revoluto, 3 $\mathrm{mm}$ de largo). Aunque con T. dirhamphis existen varios rasgos en común tales como: tamaño de la planta, tallos a veces prolíficos, inflorescencia multiflora, coloración, forma y tamaño de los sépalos, forma y tamaño de los pétalos y forma del lóbulo medio del labelo, pero el labelo tiene lóbulos basales, erectos y antrorsos (vs lóbulos no basales, patentes y redondeados), disco con un par de pequeños callos engrosados que se extienden desde la base de los lóbulos hasta casi la mitad (vs disco con un par de crestas, cada una con un pequeño diente antrorso) y clinandrio no ligulado (vs clinandrio abruptamente ligulado). Esta orquídea corresponde a una de las cuatro especies nuevas citadas en Vásquez et al. (2014).

Agradecimientos. Un agradecimiento profundo a M. López y G. Villegas que propiciaron y alentaron el estudio de orquídeas en el PN-ANMI Cotapata. Los comentarios y sugerencias de B. Collantes, D. Bogarín y un revisor anónimo coadyuvaron en gran manera a mejorar el manuscrito. A D. Trujillo por confirmar y enviar fotos de la muestra de S. trulliformis en el herbario Forestal MOL y C. Maldonado por los dibujos adicionales. Asimismo a los proyectos: "Estudio del potencial de aprovechamiento sostenible de epífitas en el Parque Nacional y Área Natural de Manejo Integrado Cotapata (PN-ANMI Cotapata)" financiado por el Fondo Flamenco para la Conservación de los Bosques Tropicales e "Inventario florístico de la región del Madidi" que apoyaron exploraciones que permitieron descubrir y colectar algunas de las especies descritas.

\section{LITERATURA CITADA}

Bennett Jr., D. E. \& Christenson E. A. (2001). Icones Orchidacearum Peruvianum, pl. 601-800. Privately published by A. Pastorelli de Bennett, Lima, t. 677.

Chase, M. W., Cameron, K. M., Freudenstein, J. V., Pridgeon, A. M., Salazar, G., van den Berg, C. \& Schuiteman, A. (2015). An updated classification of Orchidaceae. Botanical Journal of the Linnean Society, 177, 151-174.

Dodson, C. H. \& Vásquez, R. (1989a). Orchids of Bolivia. Icones Plantarum Tropicarum, Fasc. 3: plates 201-300. Missouri Botanical Garden, St. Louis.

Dodson, C. H. \& Vásquez, R. (1989b). Orchids of Bolivia. Icones Plantarum Tropicarum, Fasc. 4: plates 301-400. Missouri Botanical Garden, St. Louis.

Jiménez-Pérez, I. (2011a). Registros nuevos de orquídeas de los bosques montanos de Bolivia. Parte I. Ecología en Bolivia, 46(1), 57-61.

Jiménez-Pérez, I. (2011b). Registros nuevos de orquídeas de los bosques montanos de Bolivia. Parte II. Ecología en Bolivia, 46(1), 62-66.

Jiménez-Pérez, I. (2012). Cuatro especies nuevas de Telipogon (Orchidaceae) de los bosques montanos de Bolivia. Brittonia, 64(3), 296-304.

Jørgensen, P.M., Nee, M. H. \& Beck, S. G. (2014). Resultados. En: P. M. Jørgensen, M. H. Nee \& S. G. Beck (Eds.), Catálogo de las Plantas Vasculares de Bolivia (pp. 33-76). Monogr. Syst. Bot. Missouri Bot. Gard., 127(1-2).
Luer, C. A. (1981). Miscellaneous new species and combinations in the Pleurothallidinae (Orchidaceae). Phytologia, 49(3), 197-240.

Luer, C. A. (1983a). New species of Lepanthes (Orchidaceae). Phytologia, 54(5), 325-378.

Luer, C. A. (1983b). Miscellaneous new species in the Pleurothallidinae (Orchidaceae). Phytologia, 54(5), 379-390.

Luer, C. A. (1995). Icones Pleurothallidinarum XII. Systematics of Brachionidium (Orchidaceae). Monogr. Syst. Bot. Missouri Bot. Gard., 57, 1-146.

Luer, C. A. (1997). Icones Pleurothallidinarum XV. Systematics of Trichosalpinx. Monogr. Syst. Bot. Missouri Bot. Gard., 64, 1-118.

Luer, C. A. (1999). Four new species of Pleurothallis. Revista de la Sociedad Boliviana de Botánica, 2(2), 133-141.

Luer, C. A. (2001). Miscellaneous new species in the Pleurothallidinae. Revista de la Sociedad Boliviana de Botánica, 3(1/2), 37-63.

Vásquez, R. \& Dodson, C. H. (1982). Orchids of Bolivia. Icones Plantarum Tropicarum, Fasc. 6: plates 501-600. Selby Botanical Garden, Sarasota.

Vásquez, R. \& Dodson, C. H. (1998). Nuevas especies de orquídeas de Bolivia. Revista de la Sociedad Boliviana de Botánica, 2(1), 1-18.

Vásquez, R. \& Dodson, C. H. (1999). Nuevas especies de orquídeas de Bolivia 2. Revista de la Sociedad Boliviana de Botánica, 2(2), 143-152. 
Vásquez, R. \& Ibisch, P. L. (2000). Orquídeas de Bolivia / Orchids of Bolivia. Diversidad y estado de conservación / Diversity and conservation status. Vol. I Pleurothallidinae. Santa Cruz: Editorial FAN.

Vásquez, R. \& Dodson, C. H. (2001). Nuevas especies de orquídeas de Bolivia 3. Revista de la Sociedad Boliviana de Botánica, 3(1/2), 10-36.

Vásquez, R., Ibisch, P. L. \& Gerkmann, B. (2003). Diversity of Bolivian Orchidaceae - a challenge for taxonomic, floristic and conservation research. Organisms, Diversity \& Evolution, 3, 93-102.

Vásquez, R., Ibisch, P. L. \& Jiménez-Pérez, I. (2014). Orchidaceae. En: P. M. Jørgensen, M. H. Nee \& S. G. Beck (Eds.), Catálogo de las Plantas Vasculares de Bolivia (pp. 894-989). Monogr. Syst. Bot. Missouri Bot. Gard., 127(1-2). 